\title{
Métodos de assepsia em sementes de feijão
}

\section{Asepsis methods in bean seeds}

\author{
Yasmin Tomazi ${ }^{\circledR 1}{ }^{1}$; Lisandro Tomas da Silva Bonome ${ }^{2}$; Diogo José Siqueira ${ }^{\circledR}{ }^{3}$; \\ Gabriela Silva Moura ${ }^{4}{ }^{4}$; Gilmar Franzener ${ }^{5}{ }^{5}$
}

${ }^{1}$ Graduação em Agronomia, Universidade Federal da Fronteira Sul, Laranjeiras do Sul, yasmintomazi@ hotmail.com; ${ }^{2}$ Doutor em Agronomia, Universidade Federal da Fronteira Sul, Laranjeiras do Sul, (42) 36350000, lisandro.bonome@uffs.edu.br. ${ }^{3}$ Mestre em Agroecologia e Desenvolvimento Rural Sustentável, Universidade Federal da Fronteira Sul, Laranjeiras do Sul, (42) 36350000, diogo.siqueira@ uffs.edu.br. ${ }^{4}$ Pós-doutoranda em Agroecologia e Desenvolvimento Rural Sustentável, Universidade Federal da Fronteira Sul, Laranjeiras do Sul, (42) 36350000, bismoura@ @otmail.com. ${ }^{5}$ Doutor em Agronomia, Universidade Federal da Fronteira Sul, Laranjeiras do Sul, (42) 36350000, gilmar.franzener@uffs.edu.br.

\section{A R T I G O}

Recebido: 31/01/2018

Aprovado: 28/03/2019

\section{Palavras-chave: \\ Penicillium sp. \\ Aspergillus sp. \\ Metodologia \\ Desinfecção}

\begin{abstract}
R E S U M O
Objetivou-se avaliar diferentes métodos de assepsia e sua influência na qualidade fisiológica e sanidade de sementes de Phaseolus vulgaris L. Amostras de sementes inoculadas com os fungos Aspergillus sp. e outra com o Penicillium sp., foram submetidas aos tratamentos: controle com e sem inoculação de fungos, radiação ultravioleta (UV-C) por 1, 3 e 5 min; álcool etílico $70 \%$ por 1 e 2 min; hipoclorito de sódio $\mathrm{NaClO} 2 \%$ por 3 min com e sem adição de ácido acético; ácido peracético $1 \%$ por 3 e 6 min; termoterapia a 60 e $70{ }^{\circ} \mathrm{C}$ a seco por $5 \mathrm{~min}$ e a úmido 60 e $70{ }^{\circ} \mathrm{C}$ durante $30 \mathrm{~min}$. Avaliou-se a germinação, índice de velocidade de germinação, crescimento de plântulas, matéria fresca e seca de plântulas e a sanidade das sementes. No teste de sanidade, os tratamentos que melhor controlaram os fungos Aspergillus sp. e Penicillium sp. foram o álcool etílico $70 \%$ por 1 e $2 \mathrm{~min}, \mathrm{NaClO} 2 \%$ com e sem ácido acético e a termoterapia úmida a 60 e $70{ }^{\circ} \mathrm{C}$ por $30 \mathrm{~min}$. A termoterapia úmida a 60 e $70{ }^{\circ} \mathrm{C}$ foi eficiente no controle dos fungos, entretanto, ocasionaram mortalidade de 100 e $70 \%$ para sementes inoculadas com Aspergillus sp. e 96,5 e 98,5\% para sementes inoculadas com Penicillium sp., respectivamente. A inoculação dos fungos afetou diretamente a germinação e o vigor. Portanto, os tratamentos com álcool etílico e $\mathrm{NaClO}$ foram os mais eficientes no tratamento das sementes promovendo inibição dos fungos sem comprometer a qualidade fisiológica das sementes.
\end{abstract}

\begin{abstract}
A B S T R A C T
The aim of this work was evaluate different aseptic methods in the physiological quality and sanity of Phaseolus vulgaris L. seeds. Seed samples inoculated with fungi Aspergillus sp. and another with Penicillium sp., were submitted to the treatments: control with and without inoculation of fungi, ultraviolet (UV-C) radiation for 1, 3 and $5 \mathrm{~min}$; $70 \%$ ethyl alcohol for 1 and $2 \mathrm{~min}$; sodium hypochlorite $2 \% \mathrm{NaClO}$ for $3 \mathrm{~min}$ with addition of acetic acid; $2 \%$ $\mathrm{NaClO}$ for $3 \mathrm{~min}$; $1 \%$ peracetic acid for 3 and $6 \mathrm{~min}$; thermotherapy at 60 and $70{ }^{\circ} \mathrm{C}$ for 5 min and wet at 60 and $70^{\circ} \mathrm{C}$ for $30 \mathrm{~min}$. Germination, germination speed index, seedling growth, fresh and dry matter of seedlings and seed health were evaluated. In the sanity test, the treatments that best controlled the fungi Aspergillus sp. and Penicillium sp. were $70 \%$ ethyl alcohol for 1 and $2 \mathrm{~min}, \mathrm{NaClO} 2 \%$ with and without acetic acid and the thermotherapy at 60 and $70{ }^{\circ} \mathrm{C}$ for $30 \mathrm{~min}$. The humid thermotherapy at 60 and $70{ }^{\circ} \mathrm{C}$ was efficient in the control of fungi, however, they caused mortality of 100 and $70 \%$ for seeds inoculated with Aspergillus sp. and 96.5 and $98.5 \%$ for seeds inoculated with Penicillium sp., respectively. The inoculation of fungi directly affected germination and vigor. Therefore, the treatments with ethyl alcohol and $\mathrm{NaClO}$ were the most efficient in the treatment of the seeds promoting inhibition of the fungi without compromising the physiological quality of the seeds.
\end{abstract}

\section{INTRODUÇÃO}

O feijão comum (Phaseolus vulgaris L.) é uma planta herbácea de ciclo anual pertencente à família Fabaceae, originária do Continente Americano, onde seria cultivada há milhares de anos pela cultura Inca. Os países da América
Latina constituem o centro de maior produção e consumo de feijão. O Brasil é o maior produtor mundial, e o estado do Paraná responsável por $22 \%$ da produção de feijão nacional (DEPEC, 2017).

Além da importância econômica que esta leguminosa apresenta, destaca-se, também, a importância nutricional, por

\section{Revista Verde}

ISSN 1981-8203

Pombal, Paraíba, Brasil v. 14, n.2, abr.-jun, p.229-237, 2019 doi: $10.18378 /$ rvads.v14i2.6353 
ser uma excelente fonte proteica. Além disso, tem importância social, servindo como opção de renda e alimentação a pequenos produtores rurais, que geralmente produzem as sementes para seus próprios cultivos, mais conhecidas como sementes salva (CABRAL et al., 2011). Também é comum o uso de variedades selecionadas ao longo do tempo pelos agricultores, que apresentam maior rusticidade, resistência a doenças e capacidade de adaptação às condições do ambiente em que são cultivadas (TSUTSUMI et al., 2012). Comumente, os agricultores familiares têm preferência em semear sementes adquiridas por meio de trocas com vizinhos, familiares, feiras ou de sua própria produção. Tais sementes, em sua maioria, são armazenadas de uma safra para outra e possuem baixo controle de sanidade, apresentando elevado potencial para a incidência de patógenos associados a elas (IAPAR, 2007).

Os principais patógenos que acometem a cultura do feijoeiro são transmitidos pelas sementes, trazendo como consequências a redução da germinação e do vigor das sementes e em casos mais severos o damping off das plântulas (FERRAZ; CALVI, 2010). A assepsia em sementes é uma das medidas mais simples e eficientes no controle de doenças fúngicas, geralmente de baixo custo, fácil aplicação, além de agir diretamente na fonte de inóculo do patógeno. Este procedimento tem como objetivo impedir a introdução de novos patógenos e diminuir ou eliminar aqueles presentes nas sementes, reduzindo o número de plântulas infectadas (MANCINI; ROMANAZZI, 2014).

Sabe-se que a assepsia de sementes é um procedimento promissor para a redução de patógenos associados às sementes, entretanto é importante compreender o efeito de diferentes produtos de desinfecção sobre a qualidade fisiológica das sementes. Assim, a busca por alternativas de assepsia e/ou tratamento de sementes torna-se ainda mais importante em sistemas de base ecológica, através de técnicas de menor impacto ambiental (CARMELLO; CARDOSO, 2018).

A presença de microrganismos pode ser evitada com a utilização de produtos desinfetantes e alvejantes, mesmo que a assepsia elimine apenas os fungos associados à superfície, como os saprófitos, os quais possuem elevado potencial de interferir na sanidade das sementes (OLIVEIRA et al., 2012). O álcool etílico tem propriedades germicidas, caracterizandose como desinfetante, mas não esterilizante. Segundo Fernandes (2000) o álcool etílico a 70\%, é apontado em alguns estudos como a concentração mais eficaz, pois sua evaporação é mais lenta o que potencializa sua ação de desnaturação de proteínas na célula microbiana, aumentando o poder antimicrobiano deste em contato com os microrganismos.

Outro método é o uso do raio ultravioleta (UV-C) com comprimento de onda de $200-280 \mathrm{~nm}$, utilizado no controle de doenças de pós-colheita em frutas, também usado para redução dos danos ocasionados pelo frio e retardo do amadurecimento de frutas (OBANDE et al., 2011; BU et al., 2014). Brown et al. (2001) destacam a eficiência da utilização do UV-C em sementes de repolho à podridão negra, o uso desta radiação reduziu a densidade populacional do patógeno produzindo plantas com cor, massa e diâmetro da cabeça mais desejados.

O ácido peracético apresenta grande potencial bactericida, fungicida e esporicida, é comumente utilizado em indústrias de alimentos (NASCIMENTO et al., 2010). Sua alta capacidade de oxidação e seu amplo espectro de microrganismos o torna um excelente desinfetante mesmo em baixas concentrações (SREBRNICH, 2007).

Neste contexto, é importante conhecer a eficiência de diferentes produtos na desinfecção das sementes que sejam promissores na redução de patógenos e que, não interfiram negativamente sobre a qualidade fisiológica das mesmas. Assim, objetivou-se avaliar diferentes métodos de assepsia e sua influência na qualidade fisiológica e sanidade de sementes de Phaseolus vulgaris.

\section{MATERIAL E MÉTODOS}

As sementes de feijão, da variedade IPR Tuiuiú, safra 2018, foram obtidas de um produtor rural do Assentamento Oito de Junho do município Laranjeiras do Sul - PR. Os experimentos foram realizados no Laboratório de Germinação e Crescimento de Plantas da Universidade Federal da Fronteira Sul, Campus Laranjeiras do Sul, PR (UFFS-LS).

Os isolados fúngicos de Penicillium sp. e Aspergillus sp. foram obtidos na coleção de fungos do Laboratório de Fitopatologia da UFFS. Os fungos foram cultivados em BDA (batata-dextrose-ágar) e mantidos em BOD a $25{ }^{\circ} \mathrm{C} \pm 2{ }^{\circ} \mathrm{C}$, sem fotoperíodo por sete dias.

Foi realizado um experimento com inoculação do fungo Aspergillus sp. e outro com Penicillium sp. Para isso, as sementes foram divididas em duas amostras. A inoculação foi realizada por meio da aplicação de $5 \mathrm{~mL}$ de suspensão de conídios ajustada a 1 x $10^{5}$ conídios/mL para cada $2 \mathrm{~kg}$ de sementes. Após $24 \mathrm{~h}$ da inoculação, foram realizados os tratamentos de assepsia, que foram os seguintes: controle sem e com inoculação; UV-C por 1; 3 e 5 min; álcool $70 \%$ por 1 e 2 min; $\mathrm{NaClO} 2 \%$ por 3 min com ácido acético; $\mathrm{NaClO} 2 \%$ por $3 \mathrm{~min}$; ácido peracético $1 \%$ por 3 e $6 \mathrm{~min}$; termoterapia a seco $60^{\circ} \mathrm{C}$ e $70^{\circ} \mathrm{C}$ por $5 \mathrm{~min}$; termoterapia a úmido a 60 e 70 ${ }^{\circ} \mathrm{C}$ por $30 \mathrm{~min}$. Avaliou-se a germinação, índice de velocidade de germinação, crescimento de plântulas, matéria fresca e seca de plântulas e a sanidade das sementes.

No teste de sanidade "Blotter-test" foram utilizadas 100 sementes por tratamento, divididas em quatro repetições de 25 sementes. Estas foram distribuídas em caixas Gerbox® previamente desinfestadas com álcool $70 \%$, contendo papelfiltro umedecido com água destilada esterilizada e incubadas sob temperatura de $25 \pm 2{ }^{\circ} \mathrm{C}$ e sem fotoperíodo, por $24 \mathrm{~h}$. Logo após, foram transferidas para congelamento a temperatura de aproximadamente $-20{ }^{\circ} \mathrm{C}$ por $24 \mathrm{~h}$, e, em seguida, levada a BOD por 5 dias a $25 \pm 2{ }^{\circ} \mathrm{C}$, quando se procedeu à identificação dos patógenos, pelo método "Blotter-test" conforme Manual de Análises Sanitárias (BRASIL, 2009b). A avaliação da incidência de fungos foi realizada ao sétimo dia após a instalação do teste, quando as sementes foram observadas individualmente. Foram preparadas lâminas para observação de estruturas fúngicas e identificação. Os resultados foram expressos em porcentagem de sementes infectadas por tratamento.

$O$ teste de germinação foi realizado com quatro repetições de 50 sementes para cada tratamento. As sementes foram distribuídas sobre duas folhas de papel de germinação, umedecidas com quantidade de água equivalente a 2,5 vezes a massa do papel não hidratado, coberto com uma terceira folha e, logo após, confeccionados em forma de rolos e mantidos em germinador do tipo Mangelsdorf à temperatura de $25^{\circ} \mathrm{C}$ e luz constante. As contagens foram realizadas no quinto e nono dia. No quinto dia foram computadas as plântulas 
normais e, no nono, foram classificadas em normais, anormais, mortas e duras (BRASIL, 2009a).

$O$ Índice de Velocidade de Germinação (IVG) foi realizado em conjunto com o teste de germinação, obedecendo às prescrições das Regras para Análise de Sementes (BRASIL, 2009a). A avaliação das plântulas foi realizada diariamente, a partir do surgimento da primeira plântula normal até que o número de plântulas se tornasse constante, o IVG foi calculado pelo somatório do número de plântulas normais a cada dia, dividido pelo número de dias decorridos até à formação da plântula, utilizando como referência a fórmula proposta por Maguire (1962):

$\mathrm{IVG}=(\mathrm{G} 1 / \mathrm{N} 1)+(\mathrm{G} 2 / \mathrm{N} 2)+(\mathrm{G} 3 / \mathrm{N} 3)+\ldots+(\mathrm{Gn} / \mathrm{Nn})$.

Em que: $\mathrm{IVG}=$ índice de velocidade de emergência; $\mathrm{N}=$ número de plântulas verificadas no dia da contagem; $\mathrm{D}=$ número de dias após a semeadura em que foi realizada a contagem.

O ensaio de crescimento de plântulas foi realizado com 5 repetições de 20 sementes para cada tratamento. As sementes permaneceram em germinador do tipo Mangelsdorf à temperatura de $25^{\circ} \mathrm{C}$ e luz constante por 9 dias (BRASIL, 2009a) e, ao final do período, realizou-se a aferição do comprimento das plântulas com paquímetro digital.

Para a massa fresca de plântulas, pesou-se 10 plântulas normais, escolhidas aleatoriamente, em balança analítica de precisão de $0,01 \mathrm{~g}$, e os resultados foram expressos em $\mathrm{g}$ plântula $^{-1}$. Para a massa seca, as plântulas utilizadas na avaliação da massa fresca foram colocadas em estufa a $80{ }^{\circ} \mathrm{C}$ por $24 \mathrm{~h}$ e pesadas em balança analítica de precisão de $0,01 \mathrm{~g}$, e os resultados expressos em g plântula ${ }^{-1}$.

$\mathrm{O}$ delineamento experimental utilizado foi $\mathrm{o}$ inteiramente casualizado, com treze tratamentos e dois controles (com e sem inoculação de fungos) para as variáveis germinação e IVG e treze tratamentos e um controle (com inoculação de fungos) para os testes de sanidade de sementes, crescimento de plântulas, massa fresca e seca. Os testes de IVG, porcentagem de germinação foram conduzidos com quatro repetições de 50 sementes por tratamento, o "BlotterTest" foi conduzido com quatro repetições de 25 sementes e os testes de crescimento de plântulas, massa fresca e seca de plântula com cinco repetições de 20 sementes por tratamento. Foi realizada a comparação de médias pelo teste Scott-Knott a $5 \%$ de probabilidade. Para análise estatística os dados de sanidade foram transformados em raiz quadrada elevada $(\wedge 5)$, no programa Sisvar 5.6 (FERREIRA, 2014).

\section{RESULTADOS E DISCUSSÃO}

No teste de sanidade das sementes os tratamentos mais eficientes foram álcool $70 \%$ por 1 e 2 min, que inibiram em $100 \%$ a incidência do fungo Aspergillus sp., seguidos por $\mathrm{NaClO} 2 \%$ com e sem ácido acético, termoterapia úmida a 60 e $70{ }^{\circ} \mathrm{C}$, ácido perácetico a $1 \%$ por 6 min e UV-C por 5 e 1 min, com redução na incidência de 95; 98; 93; 78; 50; 34,78; $26 \%$ em relação ao controle com inoculação, respectivamente. Os demais tratamentos não promoveram redução significativa na incidência de Aspergillus sp. em relação ao controle com inoculação (Tabela 1). Esses resultados demonstram o efeito significativo na proteção das sementes pelo álcool etílico e $\mathrm{NaClO}$, já conhecidos e bastante utilizados como antissépticos. Outros estudos também corroboram com essa pesquisa, como os resultados obtidos por Coutinho et al. (2000), que observaram que o hipoclorito de sódio foi eficiente na redução de patógenos associados a superfície das sementes.

Tabela 1. Porcentagem de incidência de fungos e bactérias em sementes de Phaseolus vulgaris inoculado com Aspergillus sp., submetido a diferentes métodos de assepsia em sementes.

\begin{tabular}{|c|c|c|c|c|c|c|c|}
\hline Tratamentos & $\mathrm{A}$ & $\mathrm{P}$ & $\mathrm{C}$ & $\mathrm{F}$ & $\mathrm{R}$ & $\mathrm{E}$ & $\mathrm{B}$ \\
\hline Controle, com inoculação & $46,0 \mathrm{~d}$ & $24,0 \mathrm{c}$ & $16,0 \mathrm{~b}$ & $24,0 \mathrm{~b}$ & $2,0 \mathrm{a}$ & $0,0 \mathrm{a}$ & $12,0 \mathrm{a}$ \\
\hline $\mathrm{UV}-\mathrm{C}, 1 \mathrm{~min}$ & $34,0 \mathrm{c}$ & $19,0 \mathrm{c}$ & $8,0 \mathrm{~b}$ & $25,0 \mathrm{~b}$ & $0,0 \mathrm{a}$ & $0,0 \mathrm{a}$ & $23,0 \mathrm{a}$ \\
\hline UV-C, 3 min & $44,0 \mathrm{~d}$ & $14,0 \mathrm{c}$ & $5,0 \mathrm{a}$ & $20,0 \mathrm{~b}$ & $0,0 \mathrm{a}$ & $3,0 \mathrm{~b}$ & $17,0 \mathrm{a}$ \\
\hline UV-C, $5 \mathrm{~min}$ & $30,0 \mathrm{c}$ & $9,0 \mathrm{c}$ & $6,0 \mathrm{a}$ & $36,0 \mathrm{~b}$ & $0,0 \mathrm{a}$ & $0,0 \mathrm{a}$ & $23,0 \mathrm{a}$ \\
\hline Álcool $70 \%, 1 \mathrm{~min}$ & $0,0 \mathrm{a}$ & $15,0 \mathrm{c}$ & $4,0 \mathrm{a}$ & $22,0 \mathrm{~b}$ & $0,0 \mathrm{a}$ & $0,0 \mathrm{a}$ & $54,0 \mathrm{~b}$ \\
\hline Álcool 70\%, 2 min & $0,0 \mathrm{a}$ & $2,0 \mathrm{a}$ & $5,0 \mathrm{a}$ & 8,0 a & $0,0 \mathrm{a}$ & $0,0 \mathrm{a}$ & $66,0 \mathrm{c}$ \\
\hline $\mathrm{NaClO} 2 \%, 3$ min com ácido acético & $2,0 \mathrm{a}$ & $3,0 \mathrm{a}$ & $4,0 \mathrm{a}$ & $13,0 \mathrm{a}$ & $0,0 \mathrm{a}$ & $0,0 \mathrm{a}$ & $75,0 \mathrm{c}$ \\
\hline $\mathrm{NaClO} 2 \%, 3 \mathrm{~min}$ & $1,0 \mathrm{a}$ & $12,0 \mathrm{c}$ & $9,0 \mathrm{~b}$ & $12,0 \mathrm{a}$ & $2,0 \mathrm{a}$ & $0,0 \mathrm{a}$ & $73,0 \mathrm{c}$ \\
\hline Ácido peracético $1 \%, 3$ min & $43,0 \mathrm{~d}$ & $18,0 \mathrm{c}$ & $2,0 \mathrm{a}$ & $22,0 \mathrm{~b}$ & $0,0 \mathrm{a}$ & $0,0 \mathrm{a}$ & $46,0 \mathrm{~b}$ \\
\hline Ácido peracético $1 \%, 6$ min & $23,0 \mathrm{c}$ & $13,0 \mathrm{c}$ & $4,0 \mathrm{a}$ & $8,0 \mathrm{a}$ & $2,0 \mathrm{a}$ & $0,0 \mathrm{a}$ & $45,0 \mathrm{~b}$ \\
\hline Termoterapia a seco $60^{\circ} \mathrm{C}, 5 \mathrm{~min}$ & $56,0 \mathrm{~d}$ & $17,0 \mathrm{c}$ & $0,0 \mathrm{a}$ & $24,0 \mathrm{~b}$ & $0,0 \mathrm{a}$ & $0,0 \mathrm{a}$ & $11,0 \mathrm{a}$ \\
\hline Termoterapia a seco $70{ }^{\circ} \mathrm{C}, 5 \mathrm{~min}$ & $42,0 \mathrm{~d}$ & $28,0 \mathrm{c}$ & $4,0 \mathrm{a}$ & $25,0 \mathrm{~b}$ & $0,0 \mathrm{a}$ & $2,0 \mathrm{~b}$ & $13,0 \mathrm{a}$ \\
\hline Termoterapia úmida $60^{\circ} \mathrm{C}, 30 \mathrm{~min}$ & $3,0 \mathrm{a}$ & $0,0 \mathrm{a}$ & $19,0 \mathrm{~b}$ & $8,0 \mathrm{a}$ & $0,0 \mathrm{a}$ & $0,0 \mathrm{a}$ & $90,0 \mathrm{c}$ \\
\hline Termoterapia úmida $70^{\circ} \mathrm{C}, 30 \mathrm{~min}$ & $10,0 \mathrm{~b}$ & $1,0 \mathrm{a}$ & $11,0 \mathrm{~b}$ & $9,0 \mathrm{a}$ & $0,0 \mathrm{a}$ & $0,0 \mathrm{a}$ & $74,0 \mathrm{c}$ \\
\hline C.V. $(\%)$ & 27,82 & 31,82 & 38,47 & 37,80 & 6,20 & 30,97 & 18,02 \\
\hline
\end{tabular}

Médias seguidas de mesma letra nas colunas não diferem entre si para o teste de Scott-Knott a $5 \%$ de probabilidade. $\mathrm{A}=$ Aspergillus $\mathrm{sp}$.; $\mathrm{P}=$ Penicillium sp.; $\mathrm{C}=$ Cladosporium spp.; $\mathrm{F}=$ Fusarium spp.; $\mathrm{R}=$ Rhizopus spp.; E= Epicoccum $\mathrm{spp}$.; $\mathrm{B}=$ Bactéria.

Além do fungo Aspergillus sp. que foi inoculado nas sementes, também foram encontrados os gêneros de fungos Penicillium, Cladosporium, Fusarium, Rhizopus e Epicoccum spp., além de bactérias (Tabela 1).

Os tratamentos com menor incidência do fungo Penicillium sp., foram álcool 2 minutos, $\mathrm{NaClO} 2 \%$ com ácido acético, termoterapia úmida a 60 e $70{ }^{\circ} \mathrm{C}$, com as respectivas médias de $2,3,0$ e $1 \%$, que correspondem a redução na incidência de Penicillium sp. de 92; 87; 100 e $96 \%$, se comparado ao controle, respectivamente (Tabela 1).
Os tratamentos UV-C 3 e $5 \mathrm{~min}$, álcool $70 \%$ por 1 e 2 min, $\mathrm{NaClO} 2 \%$ com ácido acético, ácido peracético $1 \%$ por 3 e $6 \mathrm{~min}$, e a termoterapia a seco a 60 e $70{ }^{\circ} \mathrm{C}$ foram eficiente no controle do gênero Cladosporium, com diminuição da presença do fungo em $68 ; 62,5 ; 75 ; 68 ; 75 ; 87,5 ; 75 ; 100$ e $75 \%$, respectivamente se comparado ao controle (Tabela 1). Corroborando com os dados obtidos no presente trabalho Marquenie et al. (2002) observou a eficiência do UV-C no controle de microrganismos em frutos de pêssegos e de podridões causadas por Botrytis cinerea em morango 
(MARQUENIE et al., 2002), confirmando a ação desinfetante da radiação ultravioleta do tipo $\mathrm{C}$.

$\mathrm{O}$ ácido peracético vem tem sido utilizado na indústria alimentícia (NASCIMENTO et al., 2010). O efeito deste produto é promissor na redução de fungos e bactérias e a viabilidade dele em sementes deve ser testada em outras espécies, pois neste trabalho esta solução foi eficiente na manutenção da germinação de sementes contaminadas. Nascimento et al. (2010) destacam que o ácido peracético tem alto poder oxidante, atuando na parede celular e interior da célula microbiana prejudicando o sistema enzimático e levando a destruição do microrganismo. Se o tempo de imersão da semente na solução de ácido peracético não for elevado a ponto de ocasionar danos às células da semente, a germinação pode ser favorecida pela redução da incidência ou ausência de organismos fitopatogênicos.

Para o Fusarium spp., houve redução significativa na incidência do fungo para as sementes submetidas aos tratamentos com $\mathrm{NaClO} 2 \%$ com e sem ácido acético, álcool $70 \%$ por $2 \mathrm{~min}$, ácido peracético $1 \%$ por $6 \mathrm{~min}$ e a termoterapia úmida 60 e $70{ }^{\circ} \mathrm{C}$ de $45 ; 50 ; 66 ; 66 ; 66$ e 62,5\%, respectivamente, se comparado ao controle. Rhizopus spp. apresentou baixa incidência em todos os tratamentos, não ocorrendo diferença estatística em relação ao controle com inoculação de Aspergillus sp. O fungo do gênero Epicoccum ocorreu somente nos tratamentos com UV-C 3 minutos e termoterapia a seco $70{ }^{\circ} \mathrm{C}$, não evidenciando a presença do mesmo nos demais tratamentos (Tabela 1).

Todos os tratamentos apresentaram ocorrência de bactérias, encontrando-se as menores médias nos tratamentos com UV-C 1,3 e 5 min, termoterapia a seco 60 e $70^{\circ} \mathrm{C}$ e o controle com inoculação.

Os tratamentos que obtiveram menores médias de incidência de fungos foram os com maiores porcentagens de contaminação por bactéria provavelmente esta relação se dê por conta da antibiose e competição, ou seja, fungos e bactérias competem por espaço e nutriente e alguns deles podem produzir substâncias que inibam o crescimento de outros.

Para a porcentagem de germinação de sementes inoculadas com Aspergillus sp., observa-se que apenas o tratamento com $\mathrm{NaClO} 2 \%$ com ácido acético não diferiu do controle sem inoculação, com a maior média de germinação de $88,5 \%$. Os demais tratamentos reduziram significativamente a germinação das sementes (Tabela 2).

É conhecido que a incidência de fungos em sementes pode afetar drasticamente a germinação e o vigor das mesmas (KOVACEC et al., 2016; MANCINI; ROMANAZZI, 2014). Rocha et al. (2014) identificaram que sementes com alta incidência de Aspergillus podem afetar diretamente a fisiologia e o vigor de sementes de soja, dado que corrobora com os resultados deste trabalho, visto que apenas a inoculação com o fungo Aspergillus sp. foi responsável pela redução de $24 \%$ da germinação das sementes de feijão em relação ao controle sem inoculação (Tabela 2).

Os tratamentos que menos causaram anormalidade nas plântulas foram termoterapia a seco $60{ }^{\circ} \mathrm{C}$, ácido peracético 3 min, $\mathrm{NaClO} 2 \%$ com ácido acético e álcool $70 \%$ por 1 min não diferindo do controle sem inoculação. $\mathrm{O}$ tratamento com maior número de plântulas anormais foi o com álcool $70 \%$ por $2 \mathrm{~min}$, com média de 45,50\% (Tabela 2). Provavelmente o tempo de 2 min para imersão das sementes tenha sido suficiente para o etanol atravessar o tegumento e atingir as camadas mais internas da semente. O etanol é uma pequena molécula hidrossolúvel que pode afetar a fluidez das membranas biológicas alterando a interação normal entre lipídios e proteínas e interferindo na sua função de permeabilidade seletiva (MAIRENA, 1993).

Tabela 2. Porcentagem de germinação (\%), plântulas anormais (\%) e Índice de Velocidade de Germinação (IVG) da espécie Phaseolus vulgaris inoculado com Aspergillus sp., submetido a diferentes métodos de assepsia em sementes.

\begin{tabular}{|c|c|c|c|c|}
\hline Tratamentos & Germinação (\%) & $\begin{array}{c}\text { Plântulas Anormais } \\
(\%)\end{array}$ & $\begin{array}{c}\text { Sementes mortas } \\
(\%)\end{array}$ & $\begin{array}{l}\text { Médias de } \\
\text { IVG }\end{array}$ \\
\hline Controle, sem inoculação & $93,5 \mathrm{a}$ & $1,5 \mathrm{~d}$ & $5,0 \mathrm{e}$ & - \\
\hline Controle, com inoculação & $69,5 \mathrm{c}$ & $26,0 \mathrm{~b}$ & $4,5 \mathrm{e}$ & $7,2 \mathrm{~b}$ \\
\hline $\mathrm{UV}-\mathrm{C}, 1 \mathrm{~min}$ & $78,0 \mathrm{~b}$ & $17,0 \mathrm{c}$ & $5,0 \mathrm{e}$ & $8,4 \mathrm{a}$ \\
\hline $\mathrm{UV}-\mathrm{C}, 3 \mathrm{~min}$ & $63,5 \mathrm{~d}$ & $25,0 \mathrm{~b}$ & $11,5 \mathrm{~d}$ & $6,6 b$ \\
\hline UV-C ,5 min & $79,0 \mathrm{~b}$ & $18,0 \mathrm{c}$ & $3,0 \mathrm{e}$ & $8,2 \mathrm{a}$ \\
\hline Álcool 70\%, 1 min & $69,0 \mathrm{c}$ & $7,0 \mathrm{~d}$ & $24,0 \mathrm{c}$ & $7,6 \mathrm{a}$ \\
\hline Álcool 70\%, 2 min & $30,0 \mathrm{e}$ & $45,5 \mathrm{a}$ & $24,5 \mathrm{c}$ & $2,6 \mathrm{~d}$ \\
\hline $\mathrm{NaClO} 2 \% 3$ min com ácido acético & 88,5 a & $7,5 \mathrm{~d}$ & $4,0 \mathrm{e}$ & $9,1 \mathrm{a}$ \\
\hline $\mathrm{NaClO} 2 \%, 3 \mathrm{~min}$ & $83,5 \mathrm{~b}$ & $13,0 \mathrm{c}$ & $3,5 \mathrm{e}$ & $7,6 \mathrm{a}$ \\
\hline Ácido peracético 1\%, $3 \mathrm{~min}$ & $75,0 \mathrm{~b}$ & $9,5 \mathrm{~d}$ & $15,5 \mathrm{~d}$ & $7,7 \mathrm{a}$ \\
\hline Ácido peracético $1 \%, 6 \mathrm{~min}$ & $58,0 \mathrm{~d}$ & $28,0 \mathrm{~b}$ & $14,0 \mathrm{~d}$ & $5,7 \mathrm{c}$ \\
\hline Termoterapia a seco $60^{\circ} \mathrm{C}, 5 \mathrm{~min}$ & $78,0 \mathrm{~b}$ & $11,0 \mathrm{c}$ & $11,0 \mathrm{~d}$ & $7,7 \mathrm{a}$ \\
\hline Termoterapia a seco $70{ }^{\circ} \mathrm{C}, 5 \mathrm{~min}$ & $70,0 \mathrm{c}$ & $17,0 \mathrm{c}$ & $13,0 \mathrm{~d}$ & $7,0 \mathrm{~b}$ \\
\hline Termoterapia úmida $60^{\circ} \mathrm{C}, 30 \mathrm{~min}$ & $0,0 \mathrm{f}$ & $0,0 \mathrm{~d}$ & $100,0 \mathrm{a}$ & $0,0 \mathrm{e}$ \\
\hline Termoterapia úmida $70^{\circ} \mathrm{C}, 30 \mathrm{~min}$ & $5,5 \mathrm{f}$ & $24,5 \mathrm{~b}$ & $70,0 \mathrm{~b}$ & $0,6 \mathrm{e}$ \\
\hline C.V (\%) & 10,75 & 35,34 & 24,03 & 12,38 \\
\hline
\end{tabular}

Médias seguidas de mesma letra nas colunas não diferem entre si para o teste de Scott-Knott a 5\% de probabilidade.

A ocorrência de plântulas anormais teve relação direta com a contaminação por fungos, o que pode ser analisado, comparando o controle sem inoculação com os demais tratamentos. Esses dados reforçam o efeito prejudicial desses fungos sobre as sementes (AKONDA et al., 2016).

Os tratamentos que tiveram maior porcentagem de sementes mortas foram UV-C 3 min, ácido peracético 3 e 6 min, termoterapia seca e úmida, a 60 e $70{ }^{\circ} \mathrm{C}$. Para as sementes submetidas ao tratamento com a termoterapia úmida a $60{ }^{\circ} \mathrm{C}$, houve mortalidade de $100 \%$ das sementes (Tabela 2). Embora a termoterapia úmida tenha sido eficiente no controle dos fungos Aspergillus sp., Penicillium sp. e Fusarium sp., foi prejudicial a germinação e vigor das sementes. 
A termoterapia úmida pode causar danos fisiológicos à semente se o tempo e a temperatura não forem adequados para a espécie, pode ocorrer o rompimento das membranas e extravasamento dos metabólitos que seriam utilizados na germinação e desenvolvimento da plântula (MACHADO, 2000).Para o teste de índice de velocidade de germinação observa-se que o tratamento que menos afetou o vigor das sementes foi com $\mathrm{NaClO} 2 \%$ por 3 min com ácido acético com $88 \%$ das sementes germinadas, o qual não diferiu dos tratamentos com $\mathrm{NaClO} 2 \%$ sem ácido acético, UV-C por 5 e $1 \mathrm{~min}$, termoterapia a seco a $60{ }^{\circ} \mathrm{C}$, ácido peracético $1 \%$ por 3 min e álcool $70 \%$ por 1 min para a variável índice de velocidade de germinação.

O hipoclorito de sódio é comumente utilizado para desinfecção de ambientes e sementes. Essa solução, ao entrar em contato com a matéria orgânica, se dissocia formando $\mathrm{HOCl}$ e $\mathrm{OCl}^{-}$, sendo que a proporção entre as duas substâncias depende do $\mathrm{pH}$ da solução. Com o pH mais básico há maior formação de $\mathrm{OCl}^{-}$, que tem menor potencial desinfetante. Um pH próximo de 6 é considerado ideal, pois ocorre maior concentração de $\mathrm{HOCl}$ e sua dissociação ocorre mais lentamente, o que explica a ação do hipoclorito com ácido acético (CAMARGO et al., 2008).

O hipoclorito de sódio tem sido comumente utilizado para desinfecção de sementes, visto sua eficácia na eliminação de patógenos e seu baixo efeito fitotóxico às sementes (ROCHA et al., 2014; CARMELLLO; CARDOSO, 2018). Corroboram com o presente trabalho a pesquisa realizada por Jesus et al. (2015) que evidenciaram que o hipoclorito de sódio na concentração de $2 \%$ de cloro ativo não prejudica as partes essenciais para o processo de germinação de sementes de Carica papaya L, onde obtiveram $80 \%$ de sementes germinadas.

A termoterapia úmida foi prejudicial à germinação e o vigor das sementes estudadas. Esse método não possui proteção residual na semente e pode afetar diretamente sua qualidade fisiológica. Também é importante analisar o binômio temperatura/tempo ideal para cada espécie (LOPES; ROSSETTO, 2004; MACHADO, 2000). Para o feijão, embora a termoterapia úmida por 30 min tenha sido eficiente para o controle de fungos fitopatogênicos, esse tratamento prejudicou o desempenho fisiológico das sementes.

Corroboram com o presente trabalho, a pesquisa realizada por Santos et al. (2016) que ao estudarem o tratamento térmico $\left(40{ }^{\circ} \mathrm{C}\right)$ via úmida para controle de fitopatógenos, obtiveram sucesso na diminuição da incidência de fungos em sementes de soja, entretanto, o emprego da técnica interferiu negativamente na germinação das sementes com o tempo de exposição ao tratamento físico. Pesquisa realizada por Lazarotto et al. (2013) também evidenciaram que o tratamento térmico via calor úmido à $80^{\circ} \mathrm{C}$ por $10 \mathrm{~min}$, interferiu negativamente na qualidade fisiológica de sementes canafístula (Peltophorum dubium), e, que houve redução na germinação de sementes conforme aumentava o tempo de exposição ao tratamento físico.

Quanto ao comprimento da parte aérea e raiz, observa-se que não houve diferenças significativas entre os tratamentos quando comparados ao controle com inoculação de Aspergillus sp., exceção para os tratamentos com a termoterapia úmida que afetaram negativamente o comprimento da parte aérea e raiz e, o tratamento UV-C por 5 min que estimulou o desenvolvimento da parte aérea das plântulas de feijão (Tabela 3).

Os tratamentos UV-C por 1, 3, e 5 min, álcool $70 \%$ por 1 e 2 min, $\mathrm{NaClO} 2 \%$ com e sem ácido, termoterapia a seco 60 e $70^{\circ} \mathrm{C}$, ácido peracético por 3 e 6 min não prejudicaram o crescimento radicular em comparação ao controle com inoculação, com o maior comprimento $177,8 \mathrm{~mm}$ observado no tratamento com UV-C por 5 minutos (Tabela 3 ).

Tabela 3. Comprimento radicular e de parte aérea $(\mathrm{mm})$ das plântulas de $P$. vulgaris, onde as sementes foram submetidas a inoculação com Aspergillus sp. e após a tratamentos de desinfecção, nas sementes.

\begin{tabular}{lcc}
\hline Tratamentos & Aérea & Raiz \\
\hline Controle, com inoculação & $103,3 \mathrm{~b}$ & $139,4 \mathrm{a}$ \\
UV-C, $1 \mathrm{~min}$ & $109,4 \mathrm{~b}$ & $139,4 \mathrm{a}$ \\
UV-C, $3 \mathrm{~min}$ & $101,6 \mathrm{~b}$ & $146,3 \mathrm{a}$ \\
UV-C, $5 \mathrm{~min}$ & $147,7 \mathrm{a}$ & $177,8 \mathrm{a}$ \\
Álcool 70\%, $1 \mathrm{~min}$ & $104,7 \mathrm{~b}$ & $111,2 \mathrm{a}$ \\
Álcool 70\%, 2 min & $103,9 \mathrm{~b}$ & $96,8 \mathrm{a}$ \\
NaClO $\%, 3$ min com ácido acético & $111,6 \mathrm{~b}$ & $134,0 \mathrm{a}$ \\
NaClO $\%, 3$ min & $116,3 \mathrm{~b}$ & $154,9 \mathrm{a}$ \\
Ácido peracético $1 \%, 3$ min & $97,9 \mathrm{~b}$ & $121,9 \mathrm{a}$ \\
Ácido peracético $1 \%, 6$ min & $102,1 \mathrm{~b}$ & $132,4 \mathrm{a}$ \\
Termoterapia a seco $60^{\circ} \mathrm{C}, 5 \mathrm{~min}$ & $113,89 \mathrm{~b}$ & $126,5 \mathrm{a}$ \\
Termoterapia a seco $70^{\circ} \mathrm{C}, 5 \mathrm{~min}$ & $94,4 \mathrm{~b}$ & $152,7 \mathrm{a}$ \\
Termoterapia úmida $60^{\circ} \mathrm{C}, 30 \mathrm{~min}$ & $0,0 \mathrm{~d}$ & $0,0 \mathrm{c}$ \\
Termoterapia úmida $70^{\circ} \mathrm{C}, 30 \mathrm{~min}$ & $42,6 \mathrm{c}$ & $63,2 \mathrm{~b}$ \\
\hline C.V. $(\%)$ & 20,41 & 27,77 \\
\hline
\end{tabular}

Médias seguidas de mesma letra nas colunas não diferem entre si para o teste de Scott-Knott a $5 \%$ de probabilidade.

Na massa fresca e seca de parte aérea os tratamentos não diferiram entre si, exceção para a variável massa fresca em que o tratamento com a termoterapia úmida a 60 e $70{ }^{\circ} \mathrm{C}$ causaram mortalidade de 100 e $94 \%$ das sementes, se comparado ao controle sem inoculação (Tabela 4). Para a variável massa fresca de raiz, não houve diferença significativa entre os tratamentos. $\mathrm{Na}$ massa seca de raiz observou-se diferença significativa nos tratamentos com termoterapia úmida 60 e $70{ }^{\circ} \mathrm{C}$ que, causaram mortalidade de 100 e $92 \%$ das sementes, respectivamente, comparado ao controle, com inoculação (Tabela 4). Por outro lado, os tratamentos UV-C por $5 \mathrm{~min}$ e $\mathrm{NaClO} 2 \%$ a $3 \mathrm{~min}$, aumentaram a massa seca de raiz comparado ao controle, com inoculação (Tabela 4).

Foroughbakhch-Pournavab et al. (2015) obtiveram resultados diferente do presente trabalho em demonstraram que a exposição aos raios UV-C teve efeito negativo nas variáveis plântulas normais, massa seca e fresca das plântulas de soja. Além disso, foi observado que o aumento do tempo de exposição ao UV-C elevou a porcentagem de plântulas anormais.

Resultados semelhantes foram obtidos por Rocha et al. (2014) que observaram que o uso de hipoclorito e fungicida no tratamento de sementes de soja não interferiu negativamente nas variáveis comprimento de plântulas, massa fresca e seca das plântulas e IVE, com valores mais elevados se comparado as sementes contaminadas com Aspergillus ochraceus. 
Tabela 4. Massa fresca de parte aérea (MFPA), massa seca de parte aérea (MSPA), massa fresca de raiz (MFR) e massa seca de raiz (MSR) das plântulas de $P$. vulgaris, onde as sementes foram submetidas à inoculação com Aspergillus sp. e após a tratamentos de desinfecção, nas sementes

\begin{tabular}{|c|c|c|c|c|}
\hline Tratamentos & MFPA $(g)$ & $\operatorname{MFR}(g)$ & MSPA $(g)$ & $\operatorname{MSR}(\mathrm{g})$ \\
\hline Controle, com inoculação & $0,9548 \mathrm{a}$ & $0,2018 \mathrm{a}$ & $0,0646 \mathrm{a}$ & $0,0154 \mathrm{~b}$ \\
\hline $\mathrm{UV}-\mathrm{C}, 1 \mathrm{~min}$ & $0,9804 \mathrm{a}$ & $0,1966 \mathrm{a}$ & $0,0612 \mathrm{a}$ & $0,0144 \mathrm{~b}$ \\
\hline UV-C, 3 min & $0,9864 \mathrm{a}$ & $0,1694 \mathrm{a}$ & $0,0634 \mathrm{a}$ & $0,0144 \mathrm{~b}$ \\
\hline $\mathrm{UV}-\mathrm{C}, 5 \mathrm{~min}$ & 0,9964 a & $0,1896 \mathrm{a}$ & $0,0610 \mathrm{a}$ & $0,0180 \mathrm{a}$ \\
\hline Álcool $70 \%, 1 \mathrm{~min}$ & 0,8816 a & $0,1286 \mathrm{a}$ & $0,0700 \mathrm{a}$ & $0,0118 b$ \\
\hline Álcool 70\%, 2 min & $0,8504 \mathrm{a}$ & $0,0840 \mathrm{a}$ & $0,0644 \mathrm{a}$ & $0,0114 \mathrm{~b}$ \\
\hline $\mathrm{NaClO} 2 \%, 3$ min com ácido acético & $1,0322 \mathrm{a}$ & $0,2100 \mathrm{a}$ & $0,0678 \mathrm{a}$ & $0,0148 \mathrm{~b}$ \\
\hline $\mathrm{NaClO} 2 \%, 3 \mathrm{~min}$ & $0,9280 \mathrm{a}$ & $0,2372 \mathrm{a}$ & $0,0598 \mathrm{a}$ & $0,0184 \mathrm{a}$ \\
\hline Ácido peracético $1 \%, 3 \mathrm{~min}$ & 0,9488 a & $0,1308 \mathrm{a}$ & $0,0662 \mathrm{a}$ & $0,0134 \mathrm{~b}$ \\
\hline Ácido peracético $1 \%, 6$ min & 0,9538 a & $0,1304 a$ & 0,0626 a & $0,0116 b$ \\
\hline Termoterapia a seco $60^{\circ} \mathrm{C}, 5 \mathrm{~min}$ & $1,0608 \mathrm{a}$ & $0,1746 \mathrm{a}$ & $0,0692 \mathrm{a}$ & $0,0146 \mathrm{~b}$ \\
\hline Termoterapia a seco $70^{\circ} \mathrm{C}, 5 \mathrm{~min}$ & $1,0384 \mathrm{a}$ & $0,1616 \mathrm{a}$ & $0,0688 \mathrm{a}$ & $0,0130 \mathrm{~b}$ \\
\hline Termoterapia úmida $60^{\circ} \mathrm{C}, 30 \mathrm{~min}$ & $0,0000 \mathrm{c}$ & $0,0000 \mathrm{a}$ & $0,0000 \mathrm{a}$ & $0,0000 \mathrm{c}$ \\
\hline Termoterapia úmida $70^{\circ} \mathrm{C}, 30 \mathrm{~min}$ & $0,3472 \mathrm{~b}$ & $0,0840 \mathrm{a}$ & $0,0236 \mathrm{a}$ & $0,0072 \mathrm{~b}$ \\
\hline C.V (\%) & 19,15 & 24,81 & 26,29 & 26,58 \\
\hline
\end{tabular}

Médias seguidas de mesma letra nas colunas não diferem entre si para o teste de Scott-Knott a 5\% de probabilidade.

Com relação às sementes de feijão inoculadas com o fungo Penicillium sp. houve incidência dos gêneros Penicillium sp, Cladosporium spp, Fusarium spp, Rhizopus spp., além de bactérias. Não houve diferença estatística entre os tratamentos de desinfecção nas sementes de feijoeiro para a incidência dos fungos Aspergillus sp., Cladosporium spp. $e$ Rhizopus spp. quando comparado ao controle, com inoculação (Tabela 5).
Os tratamentos que apresentaram menor incidência de Penicillium sp. diferindo significativamente do controle com inoculação, foram álcool $70 \%$ por 1 e 2 min e a termoterapia úmida a $70{ }^{\circ} \mathrm{C}$ com redução de 93,0; 96,0 e 98,0\%, respectivamente. Para os tratamentos com $\mathrm{NaClO}$ com e sem ácido acético e termoterapia úmida de $60{ }^{\circ} \mathrm{C}$ houve inibição de $100 \%$ do fungo Penicillium sp. se comparado ao controle com inoculação (Tabela 5).

Tabela 5. Porcentagem de incidência de fungos e bactérias em sementes de Phaseolus vulgaris inoculadas com Penicillium sp., submetidas a diferentes métodos de assepsia em sementes.

\begin{tabular}{lcccccc}
\hline Tratamentos & $\mathrm{A}$ & $\mathrm{C}$ & $\mathrm{P}$ & $\mathrm{F}$ & $\mathrm{R}$ \\
\hline Controle, com inoculação & $8,0 \mathrm{a}$ & $8,0 \mathrm{a}$ & $76,0 \mathrm{a}$ & $12,0 \mathrm{~b}$ & $4,0 \mathrm{a}$ & $74,0 \mathrm{~b}$ \\
UV-C, 1 min & $4,0 \mathrm{a}$ & $9,0 \mathrm{a}$ & $78,0 \mathrm{a}$ & $19,0 \mathrm{a}$ & $2,0 \mathrm{a}$ & $93,0 \mathrm{a}$ \\
UV-C, 3 min & $7,0 \mathrm{a}$ & $8,0 \mathrm{a}$ & $67,0 \mathrm{a}$ & $21,0 \mathrm{a}$ & $0,0 \mathrm{a}$ & $91,0 \mathrm{a}$ \\
UV-C, 5 min & $7,0 \mathrm{a}$ & $16,0 \mathrm{a}$ & $51,0 \mathrm{~b}$ & $31,0 \mathrm{a}$ & $0,0 \mathrm{a}$ & $83,0 \mathrm{a}$ \\
Álcool 70\%, 1 min & $0,0 \mathrm{a}$ & $12,0 \mathrm{a}$ & $5,0 \mathrm{c}$ & $7,0 \mathrm{~b}$ & $0,0 \mathrm{a}$ & $96,0 \mathrm{a}$ \\
Álcool 70\%, 2 min & $6,0 \mathrm{a}$ & $6,0 \mathrm{a}$ & $3,0 \mathrm{c}$ & $12,0 \mathrm{~b}$ & $0,0 \mathrm{a}$ & $94,0 \mathrm{a}$ \\
NaClO 2\%, 3 min com ácido acético & $1,0 \mathrm{a}$ & $8,0 \mathrm{a}$ & $0,0 \mathrm{c}$ & $4,0 \mathrm{~b}$ & $2,0 \mathrm{a}$ & $91,0 \mathrm{a}$ \\
NaClO 2\%, 3 min & $0,0 \mathrm{a}$ & $5,0 \mathrm{a}$ & $0,0 \mathrm{c}$ & $8,0 \mathrm{~b}$ & $0,0 \mathrm{a}$ & $96,0 \mathrm{a}$ \\
Ácido peracético $1 \%, 3 \mathrm{~min}$ & $5,0 \mathrm{a}$ & $2,0 \mathrm{a}$ & $53,0 \mathrm{~b}$ & $13,0 \mathrm{~b}$ & $6,0 \mathrm{a}$ & $55,0 \mathrm{~b}$ \\
Ácido peracético $1 \%, 6 \mathrm{~min}$ & $3,0 \mathrm{a}$ & $3,0 \mathrm{a}$ & $77,0 \mathrm{a}$ & $14,0 \mathrm{~b}$ & $0,0 \mathrm{a}$ & $90,0 \mathrm{a}$ \\
Termoterapia a seco $60^{\circ} \mathrm{C}, 5 \mathrm{~min}$ & $7,0 \mathrm{a}$ & $6,0 \mathrm{a}$ & $68,0 \mathrm{a}$ & $19,0 \mathrm{a}$ & $0,0 \mathrm{a}$ & $95,0 \mathrm{a}$ \\
Termoterapia a seco $70^{\circ} \mathrm{C}, 5 \mathrm{~min}$ & $3,0 \mathrm{a}$ & $5,0 \mathrm{a}$ & $69,0 \mathrm{a}$ & $23,0 \mathrm{a}$ & $0,0 \mathrm{a}$ & $94,0 \mathrm{a}$ \\
Termoterapia úmida $60^{\circ} \mathrm{C}, 30 \mathrm{~min}$ & $0,0 \mathrm{a}$ & $10,0 \mathrm{a}$ & $0,0 \mathrm{c}$ & $7,0 \mathrm{~b}$ & $0,0 \mathrm{a}$ & $89,0 \mathrm{a}$ \\
Termoterapia úmida $70^{\circ} \mathrm{C}, 30 \mathrm{~min}$ & $0,0 \mathrm{a}$ & $8,0 \mathrm{a}$ & $1,0 \mathrm{c}$ & $2,0 \mathrm{~b}$ & $0,0 \mathrm{a}$ & $96,0 \mathrm{a}$ \\
\hline C.V $(\%)$ & 22,39 & 39,26 & 13,22 & 33,68 & 21,74 & 7,49 \\
\hline
\end{tabular}

Médias seguidas de mesma letra nas colunas não diferem entre si para o teste de Scott-Knott a $5 \%$ de probabilidade. A= Aspergillus sp.; $\mathrm{C}=$ Cladosporium spp.; $\mathrm{P}=$ Penicillium sp.; $\mathrm{F}=$ Fusarium spp.; $\mathrm{R}=$ Rhizopus spp.; $\mathrm{B}=\mathrm{Bacté}$ ia.

Redução na incidência de Penicillium sp. também foi observada em sementes de Cabralea canjerana (Vell.) Mart., tratadas com $\mathrm{NaClO}$ na concentração de $1 \%$ de cloro ativo por 2 min (AIMI et al. 2016). A assepsia de sementes com hipoclorito de sódio nas concentrações de 1 a $2 \%$ por 2 min é recomendada para sementes de espécies florestais (FERRAZ; CALVI, 2010), mas pode ser uma alternativa para a assepsia de sementes de espécies cultivadas, como o feijão. Para o fungo Fusarium spp., os tratamentos de assepsia com UV-C, 1,3 e 5 min e a termoterapia a seco 60 e $70{ }^{\circ} \mathrm{C}$ favoreceram o aumento da presença do fungo quando comparados ao controle, os demais tratamentos não apresentaram diferenças estatísticas quando comparados ao controle, inoculação com Penicillium sp. (Tabela 5).

Todos os tratamentos de assepsia estimularam a presença de bactérias nas sementes, favorecendo o aumento na incidência de bactérias quando comparado ao controle, inoculação com Penicillium sp. (Tabela 5).

Nas sementes inoculadas com Penicillium sp., todos os tratamentos reduziram significativamente a germinação das sementes, apresentando as menores médias de germinação os tratamentos com termoterapia úmida a 70 e $60{ }^{\circ} \mathrm{C}$, seguidos dos tratamentos com álcool 70\%, 2 min e termoterapia a seco $70{ }^{\circ} \mathrm{C}$ por $5 \mathrm{~min}$, com redução de 100; 98; 56 e $45 \%$ da germinação das sementes, comparado ao controle sem 
inoculação (Tabela 6). Corroborando com o presente trabalho outros autores mencionam o efeito prejudicial da termoterapia úmida na germinação e vigor de sementes (SANTOS et al., 2016; LAZAROTTO et al., 2013).

$\mathrm{Na}$ variável IVG, os tratamentos com a termoterapia a seco $70{ }^{\circ} \mathrm{C}(5,500)$, álcool $2 \mathrm{~min}$ (4,2499), a termoterapia úmida $60{ }^{\circ} \mathrm{C}(0,1416)$, a termoterapia úmida $70^{\circ} \mathrm{C}(0,0000)$, e o controle com inoculação $(3,5166)$ apresentaram menores médias em relação aos demais tratamentos, indicando redução no vigor das sementes de feijão inoculadas com Penicillium sp. Dias et al. (2003) analisando sementes de maracujá tratadas com álcool $70 \%$ observou redução linear na germinação e no vigor das sementes com o aumento do tempo de imersão das mesmas, o que evidencia o efeito fitotóxico do álcool quando em contato por muito tempo com as sementes.

A porcentagem de plântulas anormais nos tratamentos com inoculação de Penicillium sp. foi significativa. A maior anormalidade de plântulas ocorreu no controle com inoculação, com média de 53,5\%, o que evidencia o dano direto do fungo (Tabela 6). Os tratamentos com termoterapia úmida a 60 e $70{ }^{\circ} \mathrm{C}$ tiveram alta ocorrência de plântulas mortas com médias de 96,5\% e 98,5\% (Tabela 6). Assim como o ocorrido às sementes inoculadas com Aspergillus sp., a termoterapia a úmido por $30 \mathrm{~min}$ foi prejudicial para as sementes inoculadas com Penicillium sp., podendo ter afetado as membranas e extravasado os metabólitos da semente.

Tabela 6. Porcentagem de germinação (\%), plântulas anormais (\%) e Índice de Velocidade de Germinação (IVG) da espécie Phaseolus vulgaris inoculada com Penicillium sp., submetido a diferentes métodos de assepsia em sementes.

\begin{tabular}{|c|c|c|c|c|}
\hline Tratamentos & Germinação (\%) & $\begin{array}{c}\text { Plântulas Anormais } \\
(\%)\end{array}$ & $\begin{array}{c}\text { Sementes mortas } \\
(\%)\end{array}$ & Médias de IVG \\
\hline Controle, sem inoculação & $93,5 \mathrm{a}$ & $1,5 \mathrm{~d}$ & $5,0 \mathrm{c}$ & - \\
\hline Controle, com inoculação & $38,0 \mathrm{~d}$ & $53,5 \mathrm{a}$ & $8,5 \mathrm{c}$ & $3,5 \mathrm{c}$ \\
\hline $\mathrm{UV}-\mathrm{C}, 1 \mathrm{~min}$ & $69,0 \mathrm{~b}$ & $27,0 \mathrm{c}$ & $4,0 \mathrm{c}$ & $7,3 \mathrm{a}$ \\
\hline $\mathrm{UV}-\mathrm{C}, 3 \mathrm{~min}$ & $62,0 \mathrm{~b}$ & $25,0 \mathrm{c}$ & $13,0 \mathrm{~b}$ & $6,3 \mathrm{a}$ \\
\hline $\mathrm{UV}-\mathrm{C}, 5 \mathrm{~min}$ & $61,5 \mathrm{~b}$ & $29,0 \mathrm{c}$ & $9,5 \mathrm{c}$ & $6,4 \mathrm{a}$ \\
\hline Álcool $70 \%, 1 \mathrm{~min}$ & $69,0 \mathrm{~b}$ & $25,5 \mathrm{c}$ & $5.5 \mathrm{c}$ & $6,8 \mathrm{a}$ \\
\hline Álcool 70\%, 2 min & $41,0 \mathrm{~d}$ & $43,5 \mathrm{~b}$ & $15,5 \mathrm{~b}$ & $4,2 \mathrm{~b}$ \\
\hline $\mathrm{NaClO} 2 \%, 3$ min com ácido acético & $64,5 \mathrm{~b}$ & $28,0 \mathrm{c}$ & $7,5 \mathrm{c}$ & $6,7 \mathrm{a}$ \\
\hline $\mathrm{NaClO} 2 \%, 3 \mathrm{~min}$ & $64,0 \mathrm{~b}$ & $27,5 \mathrm{c}$ & $8,5 \mathrm{c}$ & $7,1 \mathrm{a}$ \\
\hline Ácido peracético $1 \%, 3 \mathrm{~min}$ & $75,0 \mathrm{~b}$ & $19,0 \mathrm{c}$ & $6,0 \mathrm{c}$ & $8,1 \mathrm{a}$ \\
\hline Ácido peracético $1 \%, 6 \mathrm{~min}$ & $65,0 \mathrm{~b}$ & $26,5 \mathrm{c}$ & $8,5 \mathrm{c}$ & 6,6 a \\
\hline Termoterapia a seco $60^{\circ} \mathrm{C}, 5 \mathrm{~min}$ & $71,5 \mathrm{~b}$ & $23,5 \mathrm{c}$ & $5,0 \mathrm{c}$ & $7,4 \mathrm{a}$ \\
\hline Termoterapia a seco $70^{\circ} \mathrm{C}, 5 \mathrm{~min}$ & $53,0 \mathrm{c}$ & $39,0 \mathrm{~b}$ & $8,0 \mathrm{c}$ & $5,5 \mathrm{~b}$ \\
\hline Termoterapia úmida $60^{\circ} \mathrm{C}, 30 \mathrm{~min}$ & $1,5 \mathrm{e}$ & $2,0 \mathrm{~d}$ & 96,5 a & $0,1 \mathrm{~d}$ \\
\hline Termoterapia úmida $70^{\circ} \mathrm{C}, 30 \mathrm{~min}$ & $0,0 \mathrm{e}$ & $1,5 \mathrm{~d}$ & $98,5 \mathrm{a}$ & $0,0 \mathrm{~d}$ \\
\hline C.V(\%) & 16,60 & 17,94 & 22,24 & 19,42 \\
\hline
\end{tabular}

Médias seguidas de mesma letra nas colunas não diferem entre si para o teste de Scott-Knott a 5\% de probabilidade.

Para o comprimento da parte aérea os tratamentos com maiores médias foram UV-C por 1,3, 5 min, álcool $70 \% 1 \mathrm{e}$ $2 \mathrm{~min}, \mathrm{NaClO} 2 \%$, ácido peracético por 3 e $6 \mathrm{~min}$, termoterapia a seco 60 e $70{ }^{\circ} \mathrm{C}$, que não diferiram do controle com inoculação. No comprimento de raiz a termoterapia a seco $70{ }^{\circ} \mathrm{C}, \mathrm{NaClO} 2 \%$ com ácido acético, termoterapia úmida 60 e $70{ }^{\circ} \mathrm{C}$ tiveram as menores médias (Tabela 7).

Tabela 7. Comprimento radicular e de parte aérea $(\mathrm{mm})$ das plântulas, com sementes submetidas a inoculação com Penicillium sp. e após a tratamentos de desinfecção

\begin{tabular}{lcc}
\hline Tratamentos & Aérea & Raiz \\
\hline Controle, com inoculação & $122,3 \mathrm{a}$ & $132,3 \mathrm{a}$ \\
UV-C, 1 min & $112,5 \mathrm{a}$ & $142,9 \mathrm{a}$ \\
UV-C, $3 \mathrm{~min}$ & $117,2 \mathrm{a}$ & $135,5 \mathrm{a}$ \\
UV-C, $5 \mathrm{~min}$ & $126,8 \mathrm{a}$ & $140,5 \mathrm{a}$ \\
Álcool 70\%, 1 min & $131,2 \mathrm{a}$ & $145,9 \mathrm{a}$ \\
Álcool 70\%, 2 min & $108,9 \mathrm{a}$ & $94,6 \mathrm{a}$ \\
NaClO 2\%, 3 min com ácido acético & $0,0 \mathrm{~b}$ & $0,0 \mathrm{c}$ \\
NaClO 2\%, 3 min & $133,2 \mathrm{a}$ & $148,6 \mathrm{a}$ \\
Ácido peracético $1 \%, 3 \mathrm{~min}$ & $130,4 \mathrm{a}$ & $144,8 \mathrm{a}$ \\
Ácido peracético $1 \%, 6 \mathrm{~min}$ & $131,4 \mathrm{a}$ & $137,9 \mathrm{a}$ \\
Termoterapia a seco $60^{\circ} \mathrm{C}, 5 \mathrm{~min}$ & $126,4 \mathrm{a}$ & $147,4 \mathrm{a}$ \\
Termoterapia a seco $70^{\circ} \mathrm{C}, 5 \mathrm{~min}$ & $91,9 \mathrm{a}$ & $52,8 \mathrm{~b}$ \\
Termoterapia úmida $60^{\circ} \mathrm{C}, 30 \mathrm{~min}$ & $0,0 \mathrm{~b}$ & $0,0 \mathrm{c}$ \\
Termoterapia úmida $70^{\circ} \mathrm{C}, 30 \mathrm{~min}$ & $0,0 \mathrm{~b}$ & $0,0 \mathrm{c}$ \\
\hline C.V. $(\%)$ & 24,78 & 28,20 \\
\hline
\end{tabular}

Médias seguidas de mesma letra nas colunas não diferem entre si para o teste de Scott-Knott a 5\% de probabilidade.
Para massa fresca de parte aérea e de raiz os tratamentos não diferiram do controle com inoculação com Penicillium sp., exceção para os tratamentos com $\mathrm{NaClO} 2 \%, 3$ min com ácido acético, termoterapia úmida 60 e $70{ }^{\circ} \mathrm{C}$ e termoterapia a seco $70{ }^{\circ} \mathrm{C}$, que apresentaram menor massa fresca. A termoterapia a seco $70{ }^{\circ} \mathrm{C}$ só diferiu do controle para massa fresca de raiz (Tabela 8). O tratamento com maior média nas duas variáveis foi o $\mathrm{NaClO} 2 \%$, com massa média de 1,4598 g.planta ${ }^{-1}$ na parte aérea e 0,2694 g.planta ${ }^{-1}$ na de raiz. Na massa seca de parte aérea os tratamentos com menores médias foram termoterapia úmida 60 e $70{ }^{\circ} \mathrm{C}$ e $\mathrm{NaClO} 2 \%$ com ácido acético. As menores médias para a massa seca de raiz foram obtidas nos tratamentos com a termoterapia úmida 60 e $70{ }^{\circ} \mathrm{C}$ e $\mathrm{NaClO} 2 \%$ com ácido acético e a termoterapia a seco $70{ }^{\circ} \mathrm{C}$. Para os demais tratamentos, não houve diferenças significativas quanto a massa seca de raiz se comparado ao controle, com inoculação (Tabela 8). Os resultados da massa fresca e da parte aérea das plântulas provenientes de sementes inoculadas Penicillium sp. apresentaram diferenças mais expressivas das obtidas a partir das sementes inoculadas por Aspergillus sp., no entanto, se manteve a mesma tendência se destacando o efeito inibitório sobre as plântulas pelos tratamentos com termoterapia úmida. 
Tabela 8. Massa fresca de parte aérea (MFPA), massa seca de parte aérea (MSPA), massa fresca de raiz (MFR) e massa seca de raiz (MSR) das plântulas de feijão, com sementes submetidas a inoculação com Penicillium sp. e após a tratamentos de desinfecção

\begin{tabular}{|c|c|c|c|c|}
\hline Tratamento & MFPA $(g)$ & $\operatorname{MFR}(\mathrm{g})$ & MSPA $(g)$ & $\operatorname{MSR}(\mathrm{g})$ \\
\hline Controle, com inoculação & $1,1844 \mathrm{a}$ & $0,2066 \mathrm{a}$ & $0,0616 \mathrm{~b}$ & $0,0142 \mathrm{a}$ \\
\hline $\mathrm{UV}-\mathrm{C}, 1 \mathrm{~min}$ & $1,0186 \mathrm{a}$ & $0,2038 \mathrm{a}$ & $0,0590 \mathrm{~b}$ & $0,0142 \mathrm{a}$ \\
\hline $\mathrm{UV}-\mathrm{C}, 3 \mathrm{~min}$ & $1,0896 \mathrm{a}$ & $0,1898 \mathrm{a}$ & $0,0566 \mathrm{~b}$ & $0,0132 \mathrm{a}$ \\
\hline $\mathrm{UV}-\mathrm{C}, 5 \mathrm{~min}$ & $0,9864 \mathrm{a}$ & $0,2064 \mathrm{a}$ & $0,0548 \mathrm{~b}$ & $0,0094 \mathrm{a}$ \\
\hline Álcool 70\%, $1 \mathrm{~min}$ & 1,1056 a & $0,2214 \mathrm{a}$ & $0,0624 \mathrm{~b}$ & $0,0152 \mathrm{a}$ \\
\hline Álcool 70\%, 2 min & $0,8840 \mathrm{a}$ & $0,1288 \mathrm{a}$ & $0,0546 \mathrm{~b}$ & $0,0094 \mathrm{a}$ \\
\hline $\mathrm{NaClO} 2 \%, 3$ min com ácido acético & $0,0000 \mathrm{~b}$ & $0,0000 \mathrm{c}$ & $0,0000 \mathrm{c}$ & $0,0000 \mathrm{c}$ \\
\hline $\mathrm{NaClO} 2 \%, 3 \mathrm{~min}$ & 1,4598 a & $0,2694 \mathrm{a}$ & $0,0882 \mathrm{a}$ & $0,0182 \mathrm{a}$ \\
\hline Ácido peracético 1\%, $3 \mathrm{~min}$ & $1,0390 \mathrm{a}$ & 0,1788 a & $0,0572 \mathrm{~b}$ & $0,0142 \mathrm{a}$ \\
\hline Ácido peracético $1 \%, 6 \mathrm{~min}$ & 1,1648 a & $0,2096 \mathrm{a}$ & $0,0628 \mathrm{~b}$ & $0,0138 \mathrm{a}$ \\
\hline Termoterapia a seco $60^{\circ} \mathrm{C}, 5 \mathrm{~min}$ & $1,1458 \mathrm{a}$ & $0,2396 \mathrm{a}$ & $0,0640 \mathrm{~b}$ & $0,0178 \mathrm{a}$ \\
\hline Termoterapia a seco $70^{\circ} \mathrm{C}, 5 \mathrm{~min}$ & $0,7374 \mathrm{a}$ & $0,1064 \mathrm{~b}$ & $0,1244 \mathrm{~b}$ & $0,0052 \mathrm{~b}$ \\
\hline Termoterapia úmida $60^{\circ} \mathrm{C}, 30 \mathrm{~min}$ & $0,0000 \mathrm{~b}$ & $0,0000 \mathrm{c}$ & $0,0000 \mathrm{c}$ & $0,0000 \mathrm{c}$ \\
\hline Termoterapia úmida $70^{\circ} \mathrm{C}, 30 \mathrm{~min}$ & $0,0000 \mathrm{~b}$ & $0,0000 \mathrm{c}$ & $0,0000 \mathrm{c}$ & $0,0000 \mathrm{c}$ \\
\hline C.V(\%) & 31,11 & 30,96 & 32,94 & 33,34 \\
\hline
\end{tabular}

Médias seguidas de mesma letra nas colunas não diferem entre si para o teste de Scott-Knott a 5\% de probabilidade.

\section{CONCLUSÃO}

O uso de álcool $70 \%$ por 1 e 2 min, $\mathrm{NaClO} 2 \%$ com e sem ácido acético e a termoterapia úmida a 60 e $70{ }^{\circ} \mathrm{C}$ por 30 min são eficientes sobre a incidência dos fungos Aspergillus sp. e Penicillium sp. em sementes de feijão, da variedade IPR Tuiuiú.

A termoterapia úmida a 60 e $70{ }^{\circ} \mathrm{C}$ por 30 min é eficiente no controle de patógenos, entretanto, causa alta mortalidade das sementes.

A inoculação dos fungos afeta diretamente a germinação e o vigor das sementes, o fungo Penicillium sp. mais agressivo que Aspergillus sp.

Os tratamentos com álcool etílico $70 \%$ por $1 \mathrm{~min}$ e hipoclorito de sódio a $2 \%$ com ácido acético são os mais indicados para a assepsia das sementes de feijão, visto que são os que menos prejudicaram a qualidade fisiológica das sementes e promovem redução na incidência de patógenos.

\section{REFERÊNCIAS}

AIMI, S. C.; ARAUJO, M. M.; MUNIZ, M. F. B.; WALKER, C. Teste de sanidade e germinação em sementes de Cabralea canjerana (Vell.) Mart. Ciência Florestal, v. 26, n. 4, p. 1361-1370, 2016. 10.5902/1980509825155.

AKONDA, M. M. R.; YASMIN, M.; HOSSAIN, I. Incidence of seedborne mycoflora and their effects on germination of maize seeds. International Journal of Agronomy and Agricultural Research (IJAAR), v. 8, n. 1, p. 87-92, 2016.

BRASIL. Manual de Análise Sanitária de Sementes. Ministério da Agricultura, Pecuária e Abastecimento. Secretaria de Defesa Agropecuária. - Brasília: Mapa/ACS, 2009b.

BRASIL. Regras para análise de sementes. Ministério da Agricultura, Pecuária e Abastecimento. Secretaria de Defesa Agropecuária. - Brasília: Mapa/ACS, 2009a.
BROWN, J. E.; LU, T. Y.; STEVENS, C.; KHAN, V. A.; LU, J. Y.; WILSON, C. L.; COLLINS, D. J.; WILSON, M. A.; IGWEGBE, E. C. K.; CHALUTZ, E.; DROBY, S. The effect of low dose ultraviolet light-C seed treatment on induced resistance in cabbage to black rot (Xanthomonas campestris pv. campestris). Crop Protection, v. 20, n. 10, p.873-883, 2001. 10.1016/S02612194(01)00037-0

BU, J.; NI, Z.; AISIKAER, G.; JIANG, Z. KHAN, Z.U.; MOU, W; YING, T. Postharvest ultraviolet-C irradiation suppressed Psy 1 and Lcy- $\beta$ expression and altered color phenotype in tomato (Solanum lycopersicum) fruit. Postharvest Biology and Technology, v. 89, p.1-6, 2014. 10.1016/j.postharvbio.2013.10.005.

CABRAL, P. D. S.; SOARES, T. C. B.; LIMA, A. B. P.; SOARES, Y. J. B.; SILVA, J. A. de. S. Análise de trilha do rendimento de grãos de feijoeiro (Phaseolus vulgaris L.) e seus componentes. Revista Ciência Agronômica, v. 42, n. 1, p. 132-138, 2011. 10.1590/S1806-66902011000100017.

CAMARGO, S. E. A.; BLANCO, T. M.; LIMA, R. Y.; RODE, S. M.; CAMARGO, C. H. R. Avaliação do pH das soluções de hipoclorito de sódio $1 \%$ e $2,5 \%$ e digluconato de clorexidina $2 \%$ em função do tempo. Revista Odontologica, v. $16, \quad$ n. $31, \quad$ p. $1-4, \quad 2008$. 10.15603/21761000/odonto.v16n31p85-91.

CARMELLO, C. R; CARDOSO, J. C. Effects of plant extracts and sodium hypochlorite on lettuce germination and inhibition of Cercospora longissima in vitro. Scientia Horticulturae, v. 234, n. 1, p. 245-249, 2018. 10.1016/j.scienta.2018.02.056.

COUTINHO W. M.; PEREIRA, L. A. A.; MACHADO, J. C.; FREITAS-SILVA, O.; PENA, R. C. M.; MAGALHÃES, F. H. L. Efeitos de hipoclorito de sódio na germinação de conídios de alguns fungos transmitidos por sementes. Fitopatologia Brasileira, v. 25, n. 3, p. 552-555, 2000. 
Departamento de Pesquisas e Estudos Econômicos. DEPEC. Acompanhamento e calendário agrícola do feijão. Junho, 2017. Disponível em: <https://www.economiaemdia.com.br/EconomiaEmDia/pdf/i nfset_feijao.pdf>. Acesso em: 19 de junho de 2018.

DIAS, J. M. M.; COUCEIRO, M. A.; VENTURA, G. M.; SIQUEIRA, D. L. de.; LIMA, J. C. de. Desinfecção e germinação in vitro de sementes do maracujazeiro. Revista Ceres, v. 50, n. 291, p. 549-564, 2003.

FERNANDES, A. T. Infecção hospitalar e suas interfaces na área da saúde. São Paulo: Atheneu; 2000.

FERRAZ, I. D. K.; CALVI, D. P. Teste de Germinação. In: LIMA JUNIOR, MJV. (Ed.). Manual de Procedimentos para Análise de Sementes Florestais. Manaus: UFAM., 2010.

FERREIRA, D. F. Sisvar: a Guide for its Bootstrap procedures in multiple comparisons. Ciência e Agroetecnologia, v. 38, n. 2, p. 109-112, 2014.

FORAUGHBAKHCH-POURNAVAB， R.; BACÓPULOSMEJÍA, E.; BENAVIDES-MENDOZA, A. Efecto de La irradiación com uv-c em La germinación y vigor de três espécies vegetales. Ecosistemas y Recursos Agropecuarios, v. 2, n.5, p.129-137, 2015.

IAPAR. Produção de sementes em pequenas propriedade/coord. Alberto Sergio Barros. $2^{\mathrm{a}}$ ed. Rev. Ampl. Londrina: IAPAR. Circular técnica, 129. p.98, 2007.

JESUS, V. A. M.; ARAÚJO, E. F.; SANTOS, F. L.; ALVES, E.; DIAS, L. A. dos. S. Sodium hypoclorite for sarcotesta remotion from papaya seeds: anatomical studies. Journal of Seed Science, v. 37, n. 4, p.228-235, 2015.

KOVAČEC, E.; LIKAR, M.; REGVAR, M. Temporal changes in fungal communities from buckwheat seeds and their effects on seed germination and seedling secondary metabolism. Fungal Biology, v. 120, n. 5, p. 666-678, 2016. 10.1016/i.funbio.2016.03.003.

LAZAROTTO M. Tratamento de sementes de canafístula via calor úmido. Revista de Ciências Agrárias v. 56, n. 3, p. 268273, 2013. 10.4322/rca.2013.038.

LOPES, F. S.; ROSSETTO, C. A. V. Qualidade de sementes de tomate influenciada pelos tratamentos térmicos e osmótico. Horticultura Brasileira, v. 22, n. 3, p. 642-646, 2004. 10.1590/S0102-05362004000300029.

MACHADO, J. C. Tratamento de sementes no controle de doenças. Lavras: Editora UFLA, 2000.

MAGUIRE, J. D. Speed of germination aid in selection and evaluation of seedling emergence and vigor. Crop Science, v. 2, p. 176-177, 1962.

MAIRENA, J. R. E. Efecto del etanol sobre las membranas biológicas. Revista Médica Hondurenha, v. 61: p. 20-24, 1993.
MANCINI, V.; ROMANAZZI, G. Seed treatments to control seedborne fungal pathogens of vegetable crops. Pest Management Science, v. 70, n.6, p. 860-868, 2014. $10.1002 /$ ps.3693

MARQUENIE D.; MICHIELS, C.W.; GEERAERD, A. H.; SCHENK, A.; SOONTJEN, C.; VAN IMPE J.F.; NICOLAÏ, B. M. Using survival analysis to investigate the effect of UVC and heat treatment on storage rot of strawberry and sweet cherry. International Journal of Food Microbiology, v 73, n. 2-3, p. 187- 196, 2002. 10.1016/S01681605(01)00648-1

NASCIMENTO HM.; DELGADO, D. A.; BARBARIC, I. F. Avaliação Da Aplicação De Agentes Sanitizantes Como Controladores Do Crescimento Microbiano $\mathrm{Na}$ Indústria Alimentícia. Revista Ceciliana, v. 2, n. 1, p.11-13, 2010.

OBANDE, M.A.; TUCKER, G.A.; SHAMA, G. Effect of preharvest UV-C treatment of tomatoes (Solanum lycopersicon Mill.) on ripening and pathogen resistance. Postharvest Biology and Technology, v.62, n.2, p.188-192, 2011. 10.1016/j.postharvbio.2011.06.001.

OLIVEIRA, J. D.; SILVA, J. B. da S.; DAPONT, E. C.; SOUZA, L. M. S. de S.; RIBEIRO, S. A. L. Métodos para detecção de fungos e assepsia de sementes de Schizolobium amazonicum (Caesalpinioideae). Bioscience of Journal, v.28, n. 6, p. 945-953, 2012.

ROCHA, F. S.; CATÃO, H. C. R. M.; BRANDÃO, A. de A.; GOMES, L. A. A. Danos causados por diferentes potenciais de inoculo de Aspergillus ochraceus no vigor de sementes de soja. Semina: Ciências Agrárias, v. 35, n. 6, p. 2895-2904, 2014. 10.5433/1679-0359.2014v35n6p2895.

SANTOS L. A.; FARIA, C. M. D. R.; MAREK, J.; DUHATSCHEK, E.; MARTINICHEN, D. Radioterapia e Termoterapia como tratamentos de sementes de Soja. Brazilian Journal of Applied Technology for Agricultural Science, v. 9, n. 2, p. 37-44, 2016. 10.5935/PAeT.

SREBERNICH, S. M. Utilização do dióxido de cloro e do ácido peracético como substitutos do hipoclorito de sódio na sanitização do cheiro-verde minimamente processado. Ciência e Tecnologia de Alimentos, v. 27, n. 4, p. 744-750, 2007. 10.1590/S0101-20612007000400012.

TSUTSUMI, C. Y.; WAGATSUMA, E.; NORETO, L. M. Cultivares de feijão produzidos em sistema de cultivo orgânico. Cultivando o Saber. v. 5, n. 3, p.123 - 131, 2012. 